\title{
Modelica in Area of Thermodynamic and Energy Systems Applications with a Focus on ClaRa Library
}

\author{
Aleš Vojáček ${ }^{1)}$ and Filip Ježek ${ }^{2,3)}$

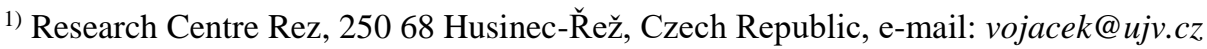 \\ ${ }^{2)}$ Creative Connections s.r. o., e-mail: filip.jezek@creativeconnections.cz \\ ${ }^{3)}$ Faculty of Electrical Engineering, Czech Technical University in Prague, Czech Republic
}

\begin{abstract}
The focus of this investigation is the development of an advanced transient model to describe the operation of a coal fired power plant which supplies electric power for a pyrometallurgy unit. Particular attention was paid to the effects of so called "downswings" (cut-off the electric arc). The performance of the unit during such failures (accumulation of energy in steam boiler during fast transient of turbine power output) was investigated using a dynamic model. The modelling of the power plant was performed on the object-oriented, multi-domain modelling language Modelica and free ClaRa library.
\end{abstract}

Keywords - transient, system modelling, Modelica, thermal hydraulics, downswings

\section{INTRODUCTION}

Over the past decades, computer simulations have become a central foundation of modern engineering. A large number of simulation tools have been developed to solve a wide range of engineering problems. This paper focuses on the analysis of a thermo-hydraulic behaviour of a coal fired $100 \mathrm{MW}$ power plant, powering a pyrometallurgy unit. The pyrometallurgy unit suffers from often "downswings", an end-point power outages, resulting in accumulation of energy in the steam boiler during fast transient of turbine power output. Coping with these events requires some modifications, especially in instrumentation and control (IC) systems, which have to be tested on detailed models.

This paper describes the first part of the study, where we verified the ability of a plant unit to work in such conditions and accumulate adequate amount of energy in the steam boiler during fast transient of the turbine power output. We analysed the increase of pressure and permissibility of this pressure peaks for the boiler and turbine technology. In a following phase, there would be introduced the necessary changes to the IC system enabling the solution of fast transient of turbine power output.

\section{Design AND Thermal ANALYSis OF Static STATES OF THE UNIT FOR SELECTED TYPES OF A DOWNSWING WITH A QUASI-STATIC MODEL}

Main objective of the static model computations is to estimate how the boiler steam production and turbine generator (further referenced to as TG) steam consumption differ during downswing occurrence. Overproduced steam at the first stage of downswing accumulates in boiler / steam pipelines and its amount determines the pressure peak. In our analyses we assumed

the downswings (or more generally, fail states in electric consumption) as given in Fig. $1(2 \times 12.5=25 \mathrm{MW}$ electric power demand reduction).

A

\begin{tabular}{|l|l|}
\hline Depth & Frequency \\
\hline $20<<25 \mathrm{MW}$ & $0.1 / \mathrm{hr}$ \\
\hline $15<<20 \mathrm{MW}$ & $1 / \mathrm{hr}$ \\
\hline $5<<15 \mathrm{MW}$ & $5 / \mathrm{hr}$ \\
\hline $0<<5 \mathrm{MW}$ & $20 / \mathrm{hr}$ \\
\hline
\end{tabular}

Fig. 1. A) Frequency of fault condition and their size, B) Type of downswings.

TG steam consumption to meet the pyrometallurgy unit power demand has been estimated by quasi-static method by means of the unit computational model created in the GateCycle software (General Electric, Boston, Massachusetts, USA). The GateCycle model has been verified and updated according to the boiler and TG provider data. It is out of the scope of the paper to describe the overall model of the plant simulated in the GateCycle. However, important are the resulted TG steam consumptions for the nominal power $(2 \times 100 \mathrm{MW}$ electric) and for the downswing $(2 \times 12.5=25 \mathrm{MW}$ electric power demand reduction) which are $290.5 \mathrm{t} / \mathrm{h}$ and $257.8 \mathrm{t} / \mathrm{h}$ respectively. These data served as input for the quasi-static analysis depicted in Fig. 2. The maximum power out recovery speed is $20 \mathrm{MW} / \mathrm{min}$., i.e. it takes $75 \mathrm{~s}$ to recover from the $25 \mathrm{MW}$ downswing. The curve of the TG steam consumption during the downswing is represented by the red colour and the rising trend can be determined by the equation $y=0.44 \cdot t+257.8$. The ideal downswing correction is an instant load decrease to compensate accumulated steam, followed by an instant increase to normalize the nominal power. Reduction of the boiler steam production after downswing occurrence is however limited. Maximum boiler load change given by the boiler supplier is $8.5 \mathrm{t} / \mathrm{h} / \mathrm{min}$ (i.e. the change in steam flow $[\mathrm{t} / \mathrm{h}$ ] per minute) both upwards and downwards. This restriction was considered in the quasi-static analysis and is depicted in Fig. 2 by the light blue colour. The decreasing trend can be determined by the equation $y=-0.14 \cdot t+290.5$.

There are several significant points on the high pressure steam (further as HP steam) production / consumption lines: 


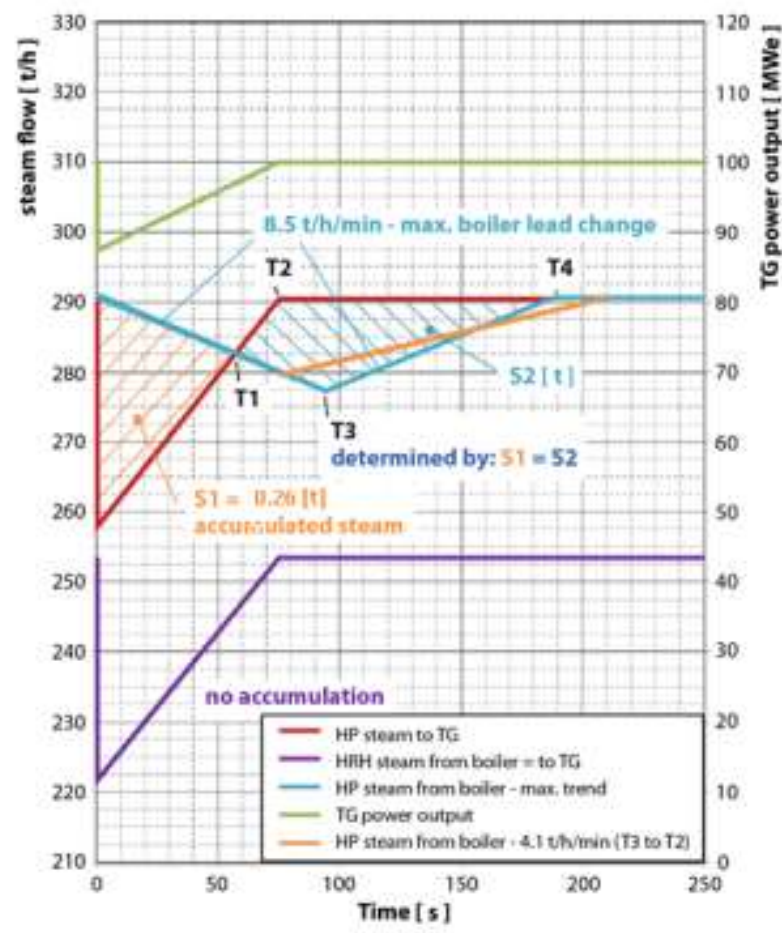

Fig. 2. Boiler and TG load after $25 \mathrm{MWe}$ downswing, with reduction of boiler maximum change to $4.1 \mathrm{t} / \mathrm{h} / \mathrm{min}$ due to shift of $\mathrm{T} 3$ to $\mathrm{T} 2$.

- At the time $t=0 \mathrm{~s}-$ start of downswing $(2 \times 12.5=$ $25 \mathrm{MW}$ el. power demand reduction).

- Steam to TG suddenly decreases and after then immediately increases to meet new required el. power output.

- Boiler starts to decrease the steam production with maximum trend $8.5 \mathrm{t} / \mathrm{h} / \mathrm{min}$.

- $\mathrm{T} 1=\sim 57 \mathrm{~s}-\mathrm{The}$ HP steam production $(y=-0.14$ $\cdot t+290.5)$ and consumption $(y=0.44 \cdot t+257.8)$ are equal. This marks the end of the HP steam accumulating phase. The amount of the accumulated steam is determined by the $\mathrm{S} 1$ area $(\mathrm{S} 1=(\mathrm{T} 1 \cdot($ downswing drop of the $\mathrm{TG}$ steam consumption)) $/ 2=0.26 t$ ). The HP steam pressure peaks here.

- $\quad \mathrm{T} 2=75 \mathrm{~s}-$ The electric power demand and the TG output are at the same level as it was before downswing.

- $\mathrm{T} 3=\sim 94 \mathrm{~s}-\mathrm{The}$ boiler starts to increase load with $\max$. trend $8.5 \mathrm{t} / \mathrm{h} / \mathrm{min}$. Time $\mathrm{T} 3$ is determined by $\mathrm{S} 1=\mathrm{S} 2$ condition. The area $\mathrm{S} 2$ can be determined by the sum of 2 triangles (T1T2T3 and T3T2T4). The Heron's formula giving the area of a general triangle was used to calculate the area of the triangle T1T2T3, where T3 was find by the help of numerical solver plugged in the MS Excel.

- $\mathrm{T} 4=\sim 188 \mathrm{~s}-$ All accumulated HP steam is discharged. The steam production and consumption are equal, i.e. end of "downswing period". T4 is the minimum time for accumulated steam discharge due to max. boiler increase load trend.

However, it is very problematic to define point $\mathrm{T} 3$ from the control system point of view, so it is necessary to "move" the point T3 to more easily identifiable point T2 (see Fig. 2). However, this requires to lower the boiler steam production trend to around $4.1 \mathrm{t} / \mathrm{h} / \mathrm{min}$ (determined by the trigonometric functions), which results in $44 \mathrm{~s}$ longer time of downswing occurrence, i.e. $232 \mathrm{~s}$.

The pressure peak can be manually calculated using the resulted accumulated amount of steam $(0.26 \mathrm{t})$ which needs to be distributed into the all steam components of the boiler and pipelines (evaporator, drum, superheater, pipeline to TG) and their corresponding parameters (steam volume, averaged steam temperature, averaged pressure) shown in Tab. 1. It was assumed that the pressure peak, namely the pressure difference between the nominal values (Tab. 2) and the pressure peaks are for each component equal. The pressure difference and the distributed accumulated steam were determined using the numerical solver plugged in the MS Excel so that volume of the steam is in each component constant. The RefProp [1] for the steam thermodynamic properties was used. The results are shown in Tab. 2.

TG steam consumption during downswing occurrence determined by the GateCycle computations has been used as an input to the Modelica model for the dynamic HP steam pressure peak evaluation.

TABLE I.

PARAMETERS OF THE STEAM INSIDE THE BOILER PARTS AND THE PIPELINE FROM THE BOILER TO THE TG (STEAM VOLUME, AVERAGED STEAM TEMPERATURE, AVERAGED PRESSURE)

\begin{tabular}{|l|l|l|l|}
\hline & $\mathrm{V}[\mathrm{m} 3]$ & $\mathrm{T}\left[{ }^{\circ} \mathrm{C}\right]$ & $\mathrm{p}[\mathrm{MPa}]$ \\
\hline evaporator & 8.1 & 342.2 & 15 \\
\hline drum & 13.2 & 342.2 & 15 \\
\hline superheater & 59.0 & 443.6 & 14.50 \\
\hline pipeline & 9.20 & 543.8 & 13.73 \\
\hline
\end{tabular}

TABLE II.

THE RESUlted PRESSURE DIFFERENCE AND THE DISTRIBUTED ACCUMUlated STEAM OF THE STEAM INSIDE THE BOILER PARTS AND THE PIPELINE FROM THE BOILER TO THE TG (STEAM VOLUME, AVERAGed Steam TEMPERATURE, AVERAGED PRESSURE)

\begin{tabular}{|l|l|l|}
\hline & $\mathrm{dp}[\mathrm{MPa}]$ & $\mathrm{dm}[\mathrm{kg}]$ \\
\hline Evaporator & 0.487 & 58 \\
\hline Drum & 0.487 & 67 \\
\hline superheater & 0.487 & 120 \\
\hline Pipeline & 0.487 & 15 \\
\hline
\end{tabular}

\section{DESIGN OF A DYNAMIC MODEL IN THE CLARA LIBRARY}

The performance of the boiler unit during downswing is simulated with a dynamic model, developed in the Modelica language within Dymola environment, using the free ClaRa library.

\section{A. Modelica}

Modelica is a specialized object-oriented equationbased language for physical modelling. It is designed for simulation of complex multi-domain systems, e.g., systems containing mechanical, electrical, electronic, hydraulic, thermal, control, electric power or processoriented subcomponents [2]. The Modelica language is based on equations and thus, on the contrary to the blockoriented languages (e.g. Simulink), the exact 
computational strategy is left to the tool itself in the compilation phase. This approach allows us to combine components (predefined or custom-built) using connectors and leave the derivation of computation causality to the machines [3]. From the authors' experience, this not only significantly saves time, but helps to avoid a number of mistakes and enables component reuse [4].

\section{B. Dymola Environment}

Several environments for the Modelica language exist For current analysis, the Dymola (version 2015, Dassault Systemes, Paris, France) has been chosen for its compatibility with the ClaRa library.

\section{ClaRa Library}

To simplify the modelling process and to avoid development of components from scratch, a number of free as well as commercial Modelica libraries are available. For this study we used the ClaRa library [5] (Clasius-Rankine cycles), designed for modelling transient thermal behaviour of power plants and power systems [6]-[8]. The ClaRa was primarily developed for the watersteam cycle and the gas path of coal dust fired boilers and heat recovery steam generators which perfectly meets our needs.

\section{Dynamic Model of the Boiler}

The dynamic model of the boiler consists of the following basic components from the ClaRa library (Fig. 3):

- Table sets value time-course and thus it is used as an input to boundary components. The time-course values are obtained from the quasi-static model described in previous chapter.

- Boundary conditions:

- mass flow inlet takes mass flow and enthalpy input,

- pressure outlet takes pressure outlet input.

- Pipe is modelled by control volumes approach, the model considers:

o dynamic energy balance for each control volume taking kinetic energy terms into account,

- dynamic mass balance for each control volume,

- dynamic momentum balance, reduced to the pressure terms coming from friction and geostatic effects,

o heat transfer to the surrounding.

- Wall takes into account the energy storage of a steel pipe walls, neglecting heat conduction in longitudinal direction.

- Drum component considers:

o dynamic mass conservation in the tank volume,

- dynamic energy conservation in the tank volume, neglecting changes in kinetic energy,

o pressure differences due to friction and geostatic pressure,

- ideal, level-dependent phase separation.

- Valve models the pressure loss according to the opening characteristics.

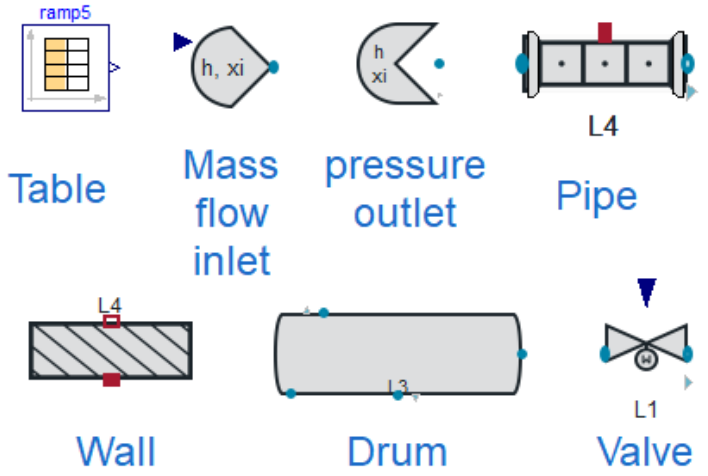

Fig. 3. Model components from the ClaRa library.

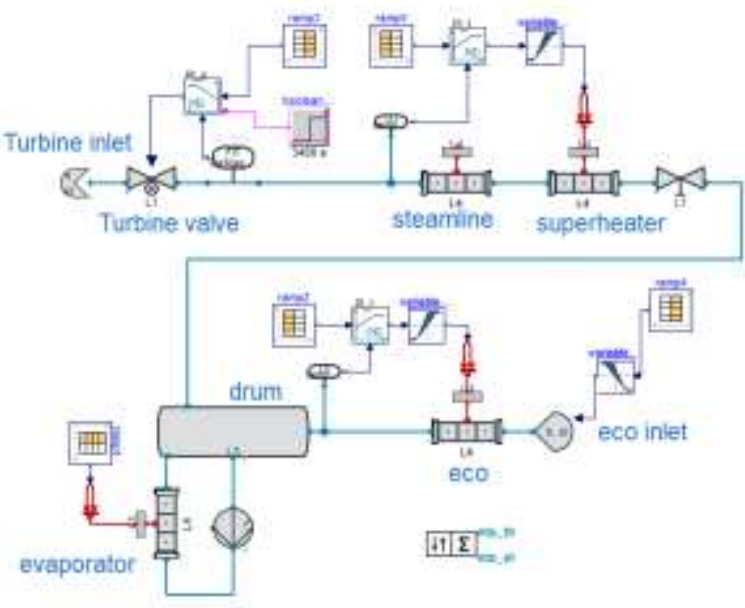

Fig. 4. The dynamic model of boiler.

The components are connected together using connectors, which enable the component design. In our model we utilize two types of connectors, the fluid connector (blue) and the thermal connector (red). They transport both non-flow (e.g. here the pressure and temperature respectively) and flow variables (mass flow rate and heat flow rate). The fluid connector in addition contains the fluid's enthalpy.

The whole model is depicted in Fig. 4. This partial model was successfully tested for 25 MW downswing.

\section{E. Validation of Model Parts and their Connection}

All partial models, thermodynamic model of boiler, dynamic model of turbine and generator and logic and continuous model of IC are to be tested separately against known inputs and expected outputs.

\section{RESULTS}

The HP steam pressure peak was evaluated by the Modelica dynamic model for the $25 \mathrm{MW}$ downswing without integration of the control system (Fig. 4). The resulted pressure peak reaches 144.5 bar at $57 \mathrm{~s}$ (absolute pressure), i.e. 4.5 bar difference from the nominal value (Fig. 5). Since the opening pressure for safety valves at HP steam is set to 151 bar, this pressure course will not cause opening them. It takes around $220 \mathrm{~s}$ for the pressure to recover from the downswing. 


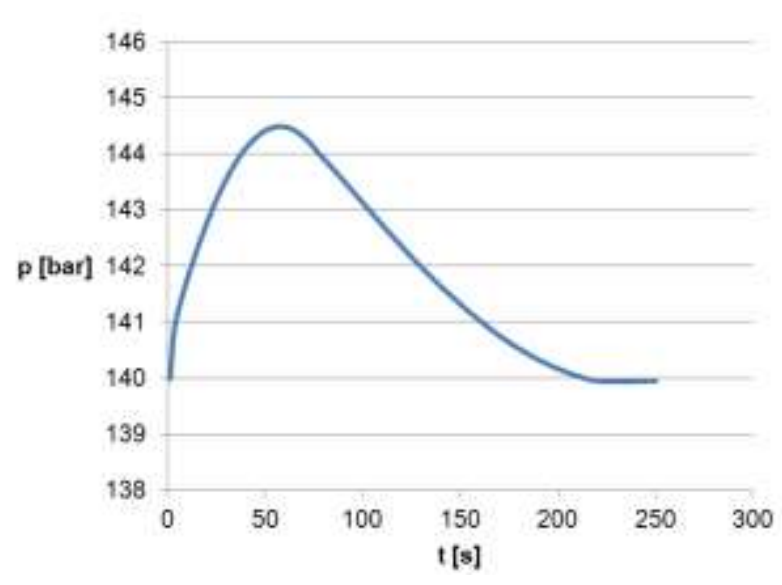

Fig. 5. Pressure propagation at superheater outlet during $25 \mathrm{MW}$ downswing.

The behaviour of the dynamic model complies with the expected values. Namely, the pressure peak occurs in around the time T1 from Fig. 2 and the pressure value corresponds to manually calculated values.
It is important to simulate all possible stationary and transient states of the unit to check, that proposed solution IC structure for downswing do not affect other stationary and transient states. The height and the shape of this pressure peak might slightly change due to the influence of the control system which was not modelled yet. This is to be analysed in the future work.

\section{DISCUSSION AND CONCLUSION}

The study demonstrates how to construct a dynamic model of the boiler in the ClaRa library. The results of the dynamic model are validated by the quasi-stationary analysis. This essential model proves, that the Modelica language together with the ClaRa library is capable of modelling complicated thermodynamic processes and greatly simplifies modelling of complex plants.

The future work would include integration of the described boiler model with turbine and IC systems. Such model would enable to test and optimize the IC systems performance on a dynamic virtual plant. The systems are already prepared (Fig. 6), but the validation has been postponed due to interruption of the whole power plant project for reasons unrelated to this paper's topic.

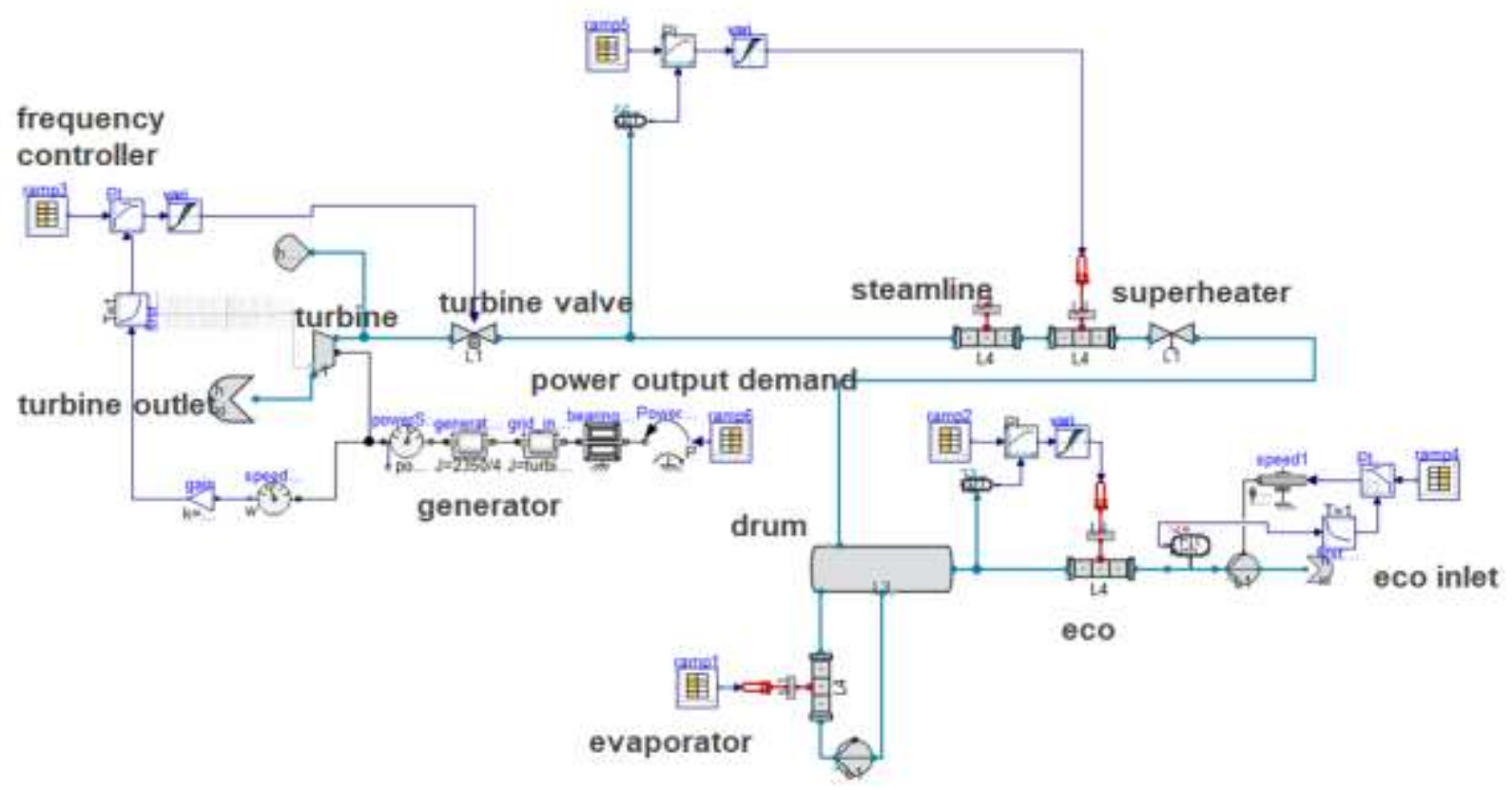

Fig. 6. Integration of the turbine and generator models with the presented boiler model.

\section{CONFLICT OF INTERESTS}

Filip Ježek provides occasional consultation and training services on the Modelica language and related products.

\section{ACKNOWLEDGMENTS}

We would like to thank to Ing. Václav Hakl and all other collaborators from the UJV Rez team, who participated on this project. 


\section{REFERENCES}

[1] NIST Reference Fluid Thermodynamic and Transport Properties Database (REFPROP): Version 10

[2] F. Casella and A. Leva, "Modelling of thermo-hydraulic power generation processes using Modelica," Math. Comput. Model. Dyn. Syst., vol. 12, no. 1, pp. 19-33, Feb. 2006. https://doi.org/10.1080/13873950500071082

[3] J. Kofránek, M. Mateják, P. Privitzer, and M. Tribula, "Causal or acausal modeling: labour for humans or labour for machines," in Technical Computing Prague, 2008, pp. 1-16.

[4] T. Kulhánek, F. Ježek, M. Mateják, J. Šilar, and J. Kofránek, "Experiences in teaching of modeling and simulation with emphasize on equation-based and acausal modeling techniques," Conf. Proc. IEEE Eng. Med. Biol. Soc., vol. 2015, pp. 36833686, Aug. 2015.

[5] Lasse Nielsen TLK-Thermo GmbH, "dynstart| ClaRa Simulation of Clausius-Rankine cycles | TLK-Thermo GmbH, Braunschweig | XRG Simulation GmbH, Hamburg | Institut für Thermofluiddynamik (TUHH), Hamburg | Institut für Energietechnik (TUHH), Hamburg." [Online]. Available: https://www.claralib.com/. [Accessed: 15-Aug-2018].

[6] J. Brunnemann et al., "Status of ClaRaCCS: Modelling and simulation of coal-fired power plants with $\mathrm{CO} 2$ capture," in Proceedings of the 9th International MODELICA Conference; September 3-5; 2012; Munich; Germany, 2012, pp. 609-618.

[7] C. Gierow, M. Hübel, J. Nocke, and E. Hassel, "Mathematical Model of Soot Blowing Influences in Dynamic Power Plant Modelling," in Proceedings of the 11th International Modelica Conference, Versailles, France, September 21-23, 2015, 2015, vol. 118, pp. 707-714.

[8] F. Gottelt, T. Hoppe, and L. Nielsen, "Applying the Power Plant Library ClaRa for Control Optimisation," in Proceedings of the 12th International Modelica Conference, Prague, Czech Republic, May 15-17, 2017, 2017, vol. 132, pp. 867-877. 